\title{
Rigidification Dramatically Improves Inhibitor Selectivity for RAF Kinases
}

\author{
Amir Assadieskandar, ${ }^{\dagger, \# \odot ~ C a i q u n ~ Y u, ~}{ }^{\dagger, \#}$ Pierre Maisonneuve, ${ }^{\S, \# \circledast{ }^{\circ}}$ Igor Kurinov, ${ }^{\perp}$ Frank Sicheri, ${ }^{\S, \|}$ \\ and Chao Zhang* $*,+\ddagger$
}

${ }^{\dagger}$ Loker Hydrocarbon Research Institute \& Department of Chemistry, University of Southern California, Los Angeles, California 90089, United States

${ }^{\ddagger}$ USC Norris Comprehensive Cancer Center, University of Southern California, Los Angeles, California 90089, United States

${ }^{\S}$ Lunenfeld-Tanenbaum Research Institute, Sinai Health System, Toronto, Ontario M5G 1X5 Canada

"Departments of Molecular Genetics and Biochemistry, University of Toronto, Toronto, Ontario, Canada

${ }^{\perp}$ Department of Chemistry and Chemical Biology, Cornell University, NE-CAT, Argonne, Illinois 60439, United States

\section{Supporting Information}

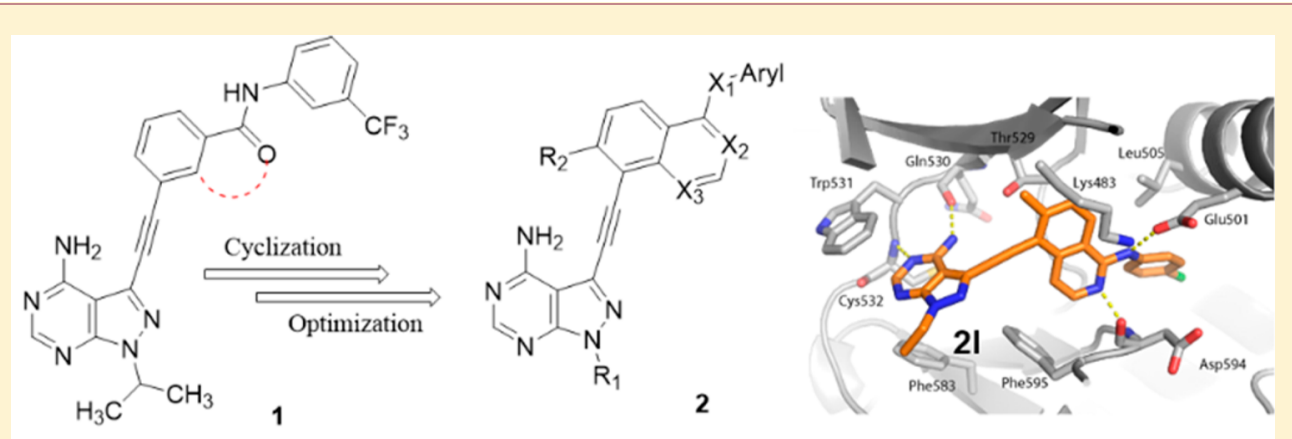

Non-selective kinase inhibitor Highly selective and potent B-Raf inhibitor

ABSTRACT: One effective means to achieve inhibitor specificity for RAF kinases, an important family of cancer drug targets, has been to target the monomeric inactive state conformation of the kinase domain, which, unlike most other kinases, can accommodate sulfonamide-containing drugs such as vemurafenib and dabrafenib because of the presence of a unique pocket specific to inactive RAF kinases. We previously reported an alternate strategy whereby rigidification of a nonselective pyrazolo[3,4-d]pyrimidine-based inhibitor through ring closure afforded moderate but appreciable increases in selectivity for RAF kinases. Here, we show that a further application of the rigidification strategy to a different pyrazolopyrimidine-based scaffold dramatically improved selectivity for RAF kinases. Crystal structure analysis confirmed our inhibitor design hypothesis revealing that $\mathbf{2 l}$ engages an active-like state conformation of BRAF normally associated with poorly discriminating inhibitors. When screened against a panel of distinct cancer cell lines, the optimized inhibitor $\mathbf{2 l}$ primarily inhibited the proliferation of the expected BRAF ${ }^{\mathrm{V} 600 \mathrm{E}}$-harboring cell lines consistent with its kinome selectivity profile. These results suggest that rigidification could be a general and powerful strategy for enhancing inhibitor selectivity against protein kinases, which may open up therapeutic opportunities not afforded by other approaches.

KEYWORDS: Rigidification, selectivity, kinase inhibitors, BRAF

$\mathrm{T}$ he RAF family kinases, consisting of ARAF, BRAF, and CRAF, are essential players in the RAS-RAF-MEK-ERK signaling pathway (also known as the mitogen-activated protein kinase pathway). They perform a central role in the regulation of cell proliferation, differentiation, and survival. ${ }^{1}$ The RAF family kinases are activated by the heterotypic or homotypic dimerization of their kinase domains. The dysregulation of the dimerization and activation of RAF kinases is a potent driver of cancer and other diseases in human. ${ }^{2}$ The most common oncogenic mutation V600E, present in $8 \%$ of all human cancers, ${ }^{3}$ constitutively activates BRAF to drive the proliferation of a variety of cancers including melanoma, colorectal cancer, and thyroid cancer. ${ }^{4}$ In particular, nearly half of human melanomas are driven by the BRAF $^{\mathrm{V} 600 \mathrm{E}}$ mutant. $^{5}$

Small-molecule RAF inhibitors have long been pursued as potential anticancer drugs. For example, sorafenib was initially developed as a RAF inhibitor over two decades ago (Figure $1)^{6,7}$ and was later shown to inhibit a variety of receptor tyrosine kinases in addition to RAF kinases. ${ }^{8}$ This multi-

Received: April 29, 2019

Accepted: June 4, 2019

Published: June 4, 2019 


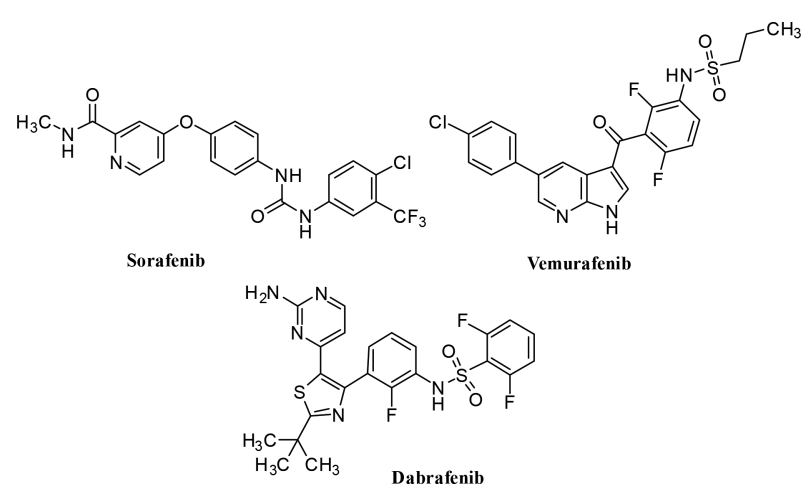

Figure 1. Chemical structures of exemplary RAF inhibitors.

targeted characteristic of sorafenib is thought to underlie its clinical efficacy against kidney and liver cancers, but its lack of specificity (and other liabilities) has limited its broad utility against other cancers such as melanomas. ${ }^{9}$ RAF inhibitors developed more recently, namely, the sulfonamides vemurafenib and dabrafenib, display greatly improved specificity and efficacy against $\mathrm{BRAF}^{\mathrm{V} 600 \mathrm{E}}$-driven melanomas leading to their approval by FDA for use in the clinic (Figure 1). ${ }^{10}$

In contrast to sorafenib, which targets the dimeric active state of BRAF that is generally similar to other protein kinases, vemurafenib and dabrafenib exhibits higher selectivity by targeting the monomeric inactive conformation of RAF defined by a laterally displaced helix $\alpha \mathrm{C}^{11,12}$ This exploited feature is not a generally shared characteristic of kinases in their inactive states. ${ }^{13,14}$ Despite their great initial efficacy, resistance to vemurafenib and dabrafenib develops rapidly in melanoma patients. Because sulfonamide inhibitors share a highly related binding mode, resistance to one inhibitor would be predicted to engender resistance to all related sulfonamide chemotypes. Thus, having inhibitors of RAF that are selective and yet target alternate conformations of the kinase domain would have value because they might overcome certain vemurafenib-resistant mutations.

We recently developed a rigidification strategy to improve inhibitor selectivity for the protein kinase BRAF. The first implementation of this strategy to a class of pyrazolopyrimidine-based (nonsulfonamide) kinase inhibitors led to a moderate increase of selectivity. ${ }^{15}$ Herein, we report that a further implementation of the strategy to nonsulfonamide pyrazolo[3,4- $d]$ pyrimidine-based inhibitors afforded a dramatic increase in selectivity for RAF kinases. Structural analysis of an optimized inhibitor confirmed our design hypothesis by revealing a binding mode that engages a dimer active-like conformation of the BRAF kinase domain. Interestingly, the optimized molecule inhibited the proliferation of cancer cells driven by $\mathrm{BRAF}^{\mathrm{V}}{ }^{600 \mathrm{E}}$ but also the proliferation of a cancer cell line NRAS ${ }^{\mathrm{Q} 61 \mathrm{R}}$, which is normally insensitive to sulfonamides.

We previously developed 3-alkynyl-pyrazolo[3,4-d]pyrimidines, exemplified as compound $\mathbf{1}$ (Figure 2), as inhibitors of Bcr-Abl. ${ }^{16}$ Although shown to be a potent inhibitor of Bcr-Abl, compound $\mathbf{1}$ inhibited many additional kinases at similar concentrations. Since our previous docking studies predicted that the benzamide groups in compound $\mathbf{1}$ was largely situated in one plane, ${ }^{16}$ we hypothesized that changing this group into an isoquinoline ring (Figure 2) would introduce rigidity into the inhibitor, resulting in preferential inhibition of conformationally more flexible kinases within the kinome. $^{15}$

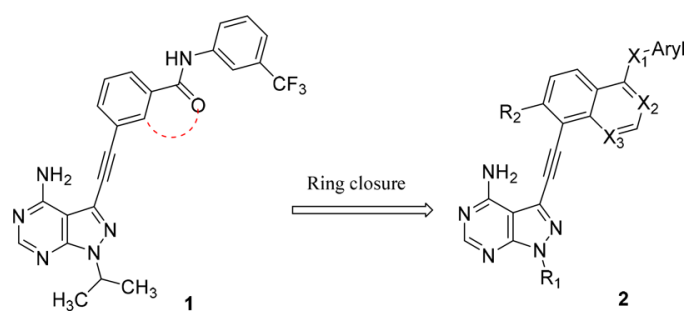

Figure 2. Cyclization of the amidobenzene group in a previously described Bcr-Abl inhibitor 1 yields compounds 2 .

To further improve kinase selectivity, a new series of alkynelinked naphtyl, isoquinoline, or quinazoline pyrazolopyrimidines were designed (Figure 2) and synthesized (Scheme 1).

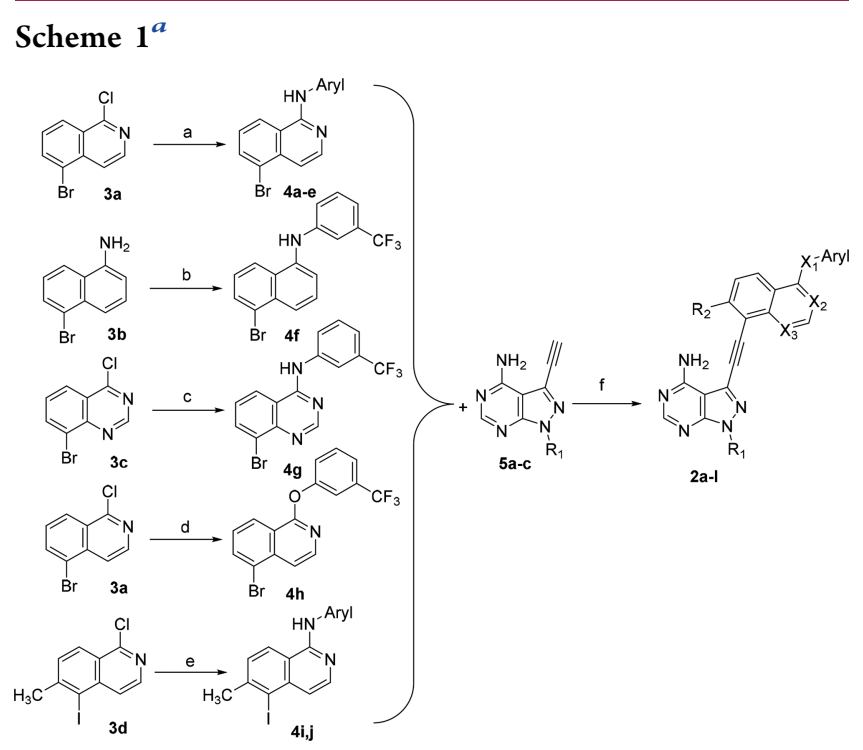

${ }^{a}$ Reagents and conditions: (a) aniline (3-(trifluoromethyl)aniline for 4a, 4-chloroaniline for $\mathbf{4 b}$, 4-chloro-3-(trifluoromethyl)aniline for $\mathbf{4 c}$, 3-(4-methyl-1H-imidazol-1-yl)-5-(trifluoromethyl)aniline for 4d, 4methyl-3-(trifluoromethyl)aniline for 4e), n-butanol, reflux; (b) 3(trifluoromethyl)phenylboronic acid, $\mathrm{Cu}(\mathrm{OAc})_{2}$, TEA, DCM; (c) 3(trifluoromethyl)aniline, isopropanol, r.t.; (d) 3-(trifluoromethyl)phenol, $\mathrm{K}_{2} \mathrm{CO}_{3}, \mathrm{CH}_{3} \mathrm{CN}$, reflux; (e) aniline (3-(trifluoromethyl)aniline for $\mathbf{4 h}$ and 4-chloro-aniline for $\mathbf{4 j}$ ), $n$-butanol, reflux; (f) $\left(\mathrm{PPh}_{3}\right)_{2} \mathrm{PdCl}_{2}$, CuI, DIPEA, DMF, $80{ }^{\circ} \mathrm{C}, \mathrm{N}_{2}$ (for $\left.4 \mathbf{a}-\mathrm{g}\right) ;\left(\mathrm{PPh}_{3}\right)_{4} \mathrm{Pd}$, CuI, TEA, DMF, r.t., $\mathrm{N}_{2}$ (for $4 \mathbf{i}, \mathbf{j}$ ).

The precursor compounds $\mathbf{3 a}-\mathbf{d}$ were either commercially available or synthesized based on previous literature methods. Compound $3 \mathrm{a}$ was synthesized via $\mathrm{N}$-oxidation of 5bromoisoquinoline with $m \mathrm{CPBA}$ followed by chlorination with phosphorus oxychloride. ${ }^{17}$ Compound $3 \mathrm{c}$ was prepared by cyclization of 2-amino-3-bromobenzoic acid in formamide followed by chlorination with phosphorus oxychloride. ${ }^{18} \mathrm{~A}$ precursor of 3d, 5-iodo-6-methylisoquinoline, was made by a sequence of transformations including nitration, reduction, and diazotization-iodination of 6-methylisoquinoline, ${ }^{19}$ and then converted into $3 \mathrm{~d}$ using similar methods to those used for preparing 3a (Scheme S1).

The intermediates 4, except $4 \mathbf{f}$, were synthesized from compounds 3 using nucleophilic aromatic substitution reactions. Compounds $\mathbf{3 a}$ and $\mathbf{3 d}$, the isoquinoline-containing precursors, were reacted with different anilines in $n$-butanol under reflux condition to yield intermediates $4 \mathbf{a}-\mathbf{e}$ and $\mathbf{4 i - j}$. ${ }^{20}$ 
Table 1. Inhibitory Activity of Compounds 2a-1 against BRAF V600E and in Vitro and in Cells<smiles></smiles>

\begin{tabular}{|c|c|c|c|c|c|c|c|c|}
\hline \multirow[b]{2}{*}{ Compounds } & \multirow[b]{2}{*}{ Aryl } & \multirow[b]{2}{*}{$\mathrm{R}_{1}$} & \multirow[b]{2}{*}{$\mathrm{R}_{2}$} & \multirow[b]{2}{*}{$\mathrm{X}_{1}$} & \multirow[b]{2}{*}{$\mathrm{X}_{2}$} & \multirow[b]{2}{*}{$\mathrm{X}_{3}$} & \multicolumn{2}{|c|}{$\mathrm{IC}_{50}(\mathrm{nM})$} \\
\hline & & & & & & & $\begin{array}{c}\text { BRAF } \\
\text { V600E }^{a}\end{array}$ & $\begin{array}{c}\mathbf{A 3 7 5}^{b} \\
\left(\mathrm{BRAF}^{\mathrm{V} 600 \mathrm{E}}\right)\end{array}$ \\
\hline $\mathbf{2 a}$ & & $i$-Pr & $\mathrm{H}$ & $\mathrm{NH}$ & $\mathrm{N}$ & $\mathrm{CH}$ & $140 \pm 28$ & $>10,000$ \\
\hline $2 b$ & & $i$-Pr & $\mathrm{H}$ & $\mathrm{NH}$ & $\mathrm{CH}$ & $\mathrm{CH}$ & $>300$ & $\mathrm{Nd}^{c}$ \\
\hline $2 c$ & & $i$-Pr & $\mathrm{H}$ & $\mathrm{NH}$ & $\mathrm{N}$ & $\mathrm{CH}$ & $29 \pm 10$ & $>10,000$ \\
\hline $2 d$ & & $i$-Pr & $\mathrm{H}$ & $\mathrm{NH}$ & $\mathrm{N}$ & $\mathrm{CH}$ & $>300$ & $\mathrm{Nd}^{c}$ \\
\hline $2 e$ & & $i$-Pr & $\mathrm{H}$ & $\mathrm{NH}$ & $\mathrm{N}$ & $\mathrm{N}$ & $>300$ & $\mathrm{Nd}^{c}$ \\
\hline $2 f$ & & $i$-Pr & $\mathrm{H}$ & $\mathrm{NH}$ & $\mathrm{N}$ & $\mathrm{CH}$ & $>300$ & $\mathrm{Nd}^{c}$ \\
\hline $2 \mathrm{~g}$ & & $i$-Pr & $\mathrm{H}$ & $\mathrm{NH}$ & $\mathrm{N}$ & $\mathrm{CH}$ & $>300$ & $\mathrm{Nd}^{c}$ \\
\hline $2 h$ & & $i$-Pr & $\mathrm{H}$ & $\mathrm{O}$ & $\mathrm{N}$ & $\mathrm{CH}$ & $>300$ & $\mathrm{Nd}^{c}$ \\
\hline $2 \mathbf{i}$ & & $i$-Pr & $\mathrm{CH}_{3}$ & $\mathrm{NH}$ & $\mathrm{N}$ & $\mathrm{CH}$ & $21 \pm 6$ & $869 \pm 79$ \\
\hline $2 \mathbf{j}$ & & Et & $\mathrm{H}$ & $\mathrm{NH}$ & $\mathrm{N}$ & $\mathrm{CH}$ & $41 \pm 6$ & $>10,000$ \\
\hline $2 k$ & & $n$-Pr & $\mathrm{H}$ & $\mathrm{NH}$ & $\mathrm{N}$ & $\mathrm{CH}$ & $>300$ & $\mathrm{Nd}^{c}$ \\
\hline 21 & & Et & $\mathrm{CH}_{3}$ & $\mathrm{NH}$ & $\mathrm{N}$ & $\mathrm{CH}$ & $8 \pm 1$ & $417 \pm 39$ \\
\hline Vem & & & & & & & $21 \pm 7$ & $127 \pm 3$ \\
\hline
\end{tabular}

${ }^{a} \mathrm{IC}_{50}$ values were determined by following the in vitro kinase assay protocols. The data represent the mean values of two independent experiments. ${ }^{b}$ Growth inhibition was determined using MTT assay. A375 cells were plated in 96-well plates at $1 \times 10^{3}$ cells per well and incubated with different concentrations of the inhibitor for $96 \mathrm{~h}$. The data represent the mean values of two independent experiments, each carried out in triplicates. ${ }^{c} \mathrm{Nd}$ : not determined.

Compound 4f was made by coupling 3-(trifluoromethyl)phenylboronic acid with 5-bromonaphthalen-1-amine in the presence of cupric acetate and triethylamine in DCM. ${ }^{21}$ To prepare the quinazoline-containing intermediate $\mathbf{4 g}$, a milder condition involving isopropanol as solvent at room temperature was used. ${ }^{18}$ The oxygen-linked intermediate $4 \mathrm{~h}$ was synthesized by refluxing 3-(trifluoromethyl)phenol, 5-bromo1-chloroisoquinoline, and $\mathrm{K}_{2} \mathrm{CO}_{3}$ in acetonitrile. ${ }^{22}$

The precursors $\mathbf{5 a - c}$ were prepared using reported procedures with slight modifications. ${ }^{23}$ 3-Iodo- $1 H$-pyrazolo$[3,4-d]$ pyrimidin-4-amine was first treated with alkyl halides to install alkyl groups at the 1 position (Scheme S2). The resulting intermediates underwent Sonogashira coupling 
reactions with trimethylsilyl acetylene and then deprotection to produce $\mathbf{5 a}-\mathbf{c}$. In the final step, coupling of the alkyne intermediates $\mathbf{5 a}-\mathbf{c}$ with the aryl halides $\mathbf{4 a}-\mathbf{j}$ afforded the final compounds $\mathbf{2 a - 1}$ (Scheme 1). ${ }^{15}$

We chose $\mathbf{2} \mathbf{a}$ as a representative of the panel of synthesized compounds (Table 1) because of its closest structural similarity to the parent compound $\mathbf{1}$ and evaluated its kinome inhibition profile against 245 protein kinases in comparison with 1 (Table S1). Consistent with our previously reported profiling results against a smaller panel of kinases, ${ }^{24}$ the selectivity of 1 was rather poor, inhibiting 42 kinases in the panel by over $85 \%$ activity at $1 \mu \mathrm{M}$. In contrast, compound $2 \mathrm{a}$ showed drastically improved selectivity, inhibiting only BRAF and CRAF, by over $85 \%$ activity (Figure 3 ). Hence, a rigidification strategy implemented via ring closure here greatly improved the specificity characteristics of the promiscuous inhibitor 1.

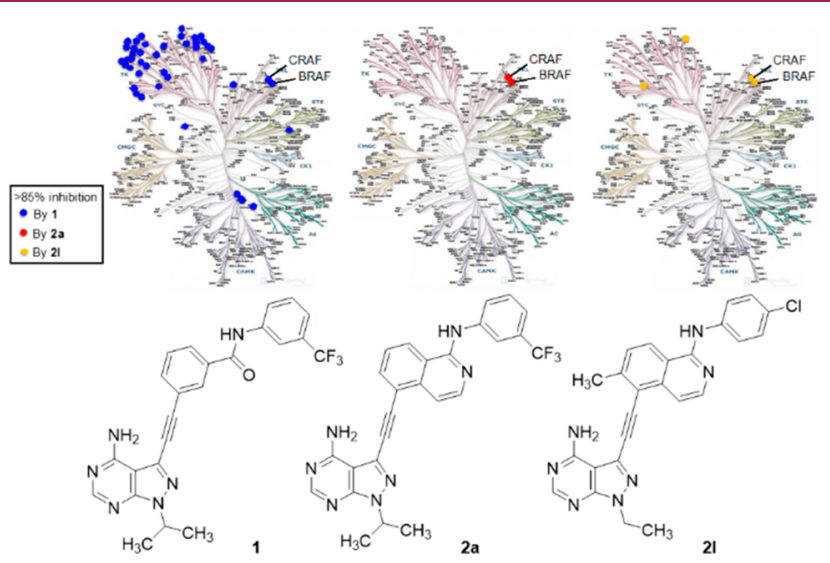

Figure 3. Kinome inhibition profiles of compounds $\mathbf{1}$ and $\mathbf{2 a}$ illustrated in a phylogenetic tree format. The inhibitors were screened against 245 kinases at $1 \mu \mathrm{M}$. The kinases that were $>85 \%$ inhibited by $\mathbf{1}, \mathbf{2 a}$, and $\mathbf{2 l}$ are colored blue, red, and orange, respectively, on the kinome trees.

Since the kinome profiling experiment showed that compound 2 a possessed an improved specificity profile for RAF kinases, we next sought to explore the activity characteristics of the full compound series $2 a-1$ against BRAF, with the goal of identifying a specific lead with greatest potency. To this end we performed dose-response analyses against $\mathrm{BRAF}^{\mathrm{V} 600 \mathrm{E}}$ activity in vitro (Table 1 ). Vemurafenib, employed as a control, displayed an $\mathrm{IC}_{50}$ value of $21 \mathrm{nM}$, consistent with the value reported previously. ${ }^{25}$ Compounds $2 a, 2 c, 2 i$, and $2 \mathbf{j}$ inhibited $B A^{\mathrm{V} 600 \mathrm{E}}$ with $\mathrm{IC}_{50}$ values ranging between 21 to $140 \mathrm{nM}$, while compounds $2 \mathbf{b}, 2 \mathrm{~d}, 2 \mathrm{e}, 2 \mathrm{f}, \mathbf{2 g}, \mathbf{2 h}$ and $2 \mathbf{k}$ inhibit $\mathrm{BRAF}^{\mathrm{V} 600 \mathrm{E}}$ with $\mathrm{IC}_{50}$ values greater than $300 \mathrm{nM}$ (Figure S1). The structure-activity relationship (SAR) analysis indicated that a para-chloro substituent on the anilino moiety (as in $2 c$ ) confers a 4-fold increase in affinity relative to a meta-trifluoromethyl substituent (as in $\mathbf{2 a}$ ). Furthermore, a methyl group at position 6 of the isoquinoline ring confers a 7fold increase in affinity (comparing $2 \mathbf{a}$ with $\mathbf{2 i}$ ), while an ethyl group at position 1 of the pyrazolopyrimidine relative to an isopropyl group confers a 3 -fold increase in affinity to BRAF (comparing $2 \mathrm{a}$ and $\mathbf{2 j}$ ). Gratifyingly, when the favored substituents at each position were combined, the resulting compound 21 exhibited the highest potency in the series with an $\mathrm{IC}_{50}$ of $8 \mathrm{nM}$ against BRAF ${ }^{\mathrm{V} 600 \mathrm{E}}$. This corresponded to an
18 -fold increase in affinity relative to $2 \mathrm{a}$. Notably, the potency of 21 was over 2 -fold more potent than vemurafenib in the same assay.

We next profiled 21 at $1 \mu \mathrm{M}$ against 245 kinases as performed for $\mathbf{1}$ and $\mathbf{2 a}$ and observed a slight reduction of selectivity against RAFs with just four kinases, specifically BRAF, CRAF, BRK, and FMS, inhibited by more than $85 \%$ (Figure 3; Table S1). Importantly, this result demonstrated that the specificity characteristics arising from our original rigidification strategy were largely maintained following lead optimization.

Having shown that a few rigidified inhibitors were both specific and potent at inhibiting BRAF in vitro, we next investigated the effect of the five most potent inhibitors (2a, $2 \mathbf{c}, \mathbf{2 i}, \mathbf{2} \mathbf{j}$, and $2 \mathbf{l}$ ) on the proliferation of A375 cells harboring the $\mathrm{BRAF}^{\mathrm{V} 600 \mathrm{E}}$ mutant (Table 1). ${ }^{26}$ Notably, 2l, the most potent inhibitor of $\mathrm{BRAF}^{\mathrm{V} 600 \mathrm{E}}$ of the panel in vitro, also displayed the highest potency at inhibiting the proliferation of A375 cells, with an $\mathrm{IC}_{50}$ of $417 \mathrm{nM}$, only 3-fold worse than vemurafenib $\left(\mathrm{IC}_{50}=127 \mathrm{nM}\right)$. The diminished potency of 21 relative to vemurafenib in cells was not unexpected considering that as an FDA-approved drug vemurafenib has been greatly optimized for permeability and bioavailability. In conclusion, the optimized compound, 2l, was effective at suppressing the proliferation of $\mathrm{BRAF}^{\mathrm{V} 600 \mathrm{E}}$-driven cells, in agreement with its potent inhibition of $\mathrm{BRAF}^{\mathrm{V} 600 \mathrm{E}}$ in vitro.

We next compared the effects of 21 with vemurafenib on downstream signaling in A375 cells. In these cells, expression of the active mutant $\mathrm{BRAF}^{\mathrm{V} 600 \mathrm{E}}$ leads to constitutively elevated levels of phospho-ERK ( $\mathrm{pERK}$ ), which provides a useful marker for effects on pathway signaling. In agreement with a previous report, ${ }^{25}$ vemurafenib repressed pERK levels with an $\mathrm{IC}_{50}$ of $80 \mathrm{nM}$, whereas 21 inhibited phospho-ERK levels with an $\mathrm{IC}_{50}$ of $420 \mathrm{nM}$ (Figure 4). These results were consistent

\begin{tabular}{|c|c|c|c|c|c|c|c|c|c|c|c|}
\hline \multirow[b]{2}{*}{0} & \multicolumn{4}{|c|}{ VEM } & \multicolumn{6}{|c|}{21} & \multirow[b]{2}{*}{$\mu \mathrm{M}$} \\
\hline & 0.10 .3 & 1.0 & 3.0 & 10 & 0 & 0.1 & 0.3 & 1.0 & 3.0 & 10 & \\
\hline 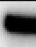 & $-1=$ & $=$ & $x^{2}$ & 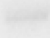 & $=$ & - & - & $=$ & $=$ & $\omega$ & pERK \\
\hline & 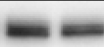 & - & $=$ & & $=$ & $=$ & $=$ & 0 & 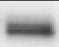 & 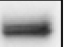 & ERK \\
\hline
\end{tabular}

Figure 4. Effects of vemurafenib and compound $\mathbf{2 l}$ on downstream signaling of $\mathrm{BRAF}^{\mathrm{V} 600 \mathrm{E}}$ in $\mathrm{A} 375$ cells. Vemurafenib and 21 inhibited the phosphorylation of ERK with $\mathrm{IC}_{50}$ values of 80 and $420 \mathrm{nM}$, respectively.

with the relative potency of $\mathbf{2 1}$ in the A375 cell proliferation assay (Table 1). In sum, our data showed we could use a rigidification strategy to design a highly specific inhibitor that was both potent in vitro and in A375 cells.

To determine the binding mode of $2 \mathbf{l}$, we solved its costructure in complex with the BRAF kinase domain to 3.05 $\AA$ resolution $\left(R_{\text {work }} / R_{\text {free }}=23.5 / 27.5\right.$; Table S2 $)$. Unbiased electron density in the ATP binding pocket of each kinase domain allowed unambiguous modeling of $\mathbf{2 l}$ in BRAF (Figure $5 A)$.

The kinase domain of RAF adopted the characteristic sideto-side dimer configuration reflective of a kinase active-like state (Figure S2A). This configuration, defined by a productive inward conformation of helix $\alpha \mathrm{C}$, is also notably preferred by the poorly selective, nonsulfonamide inhibitor sorafenib and contrasts with the monomeric inactive-like conformation of the 


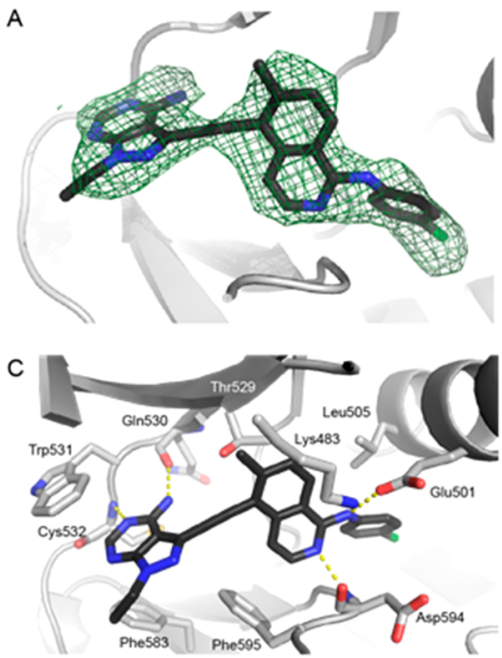

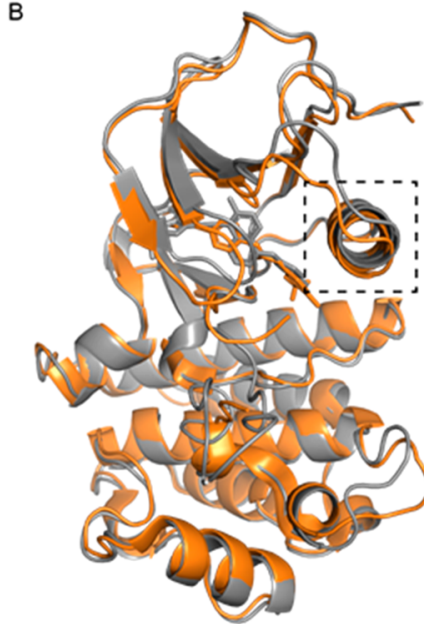

BRAF:2l vS BRAF:Sorafenib

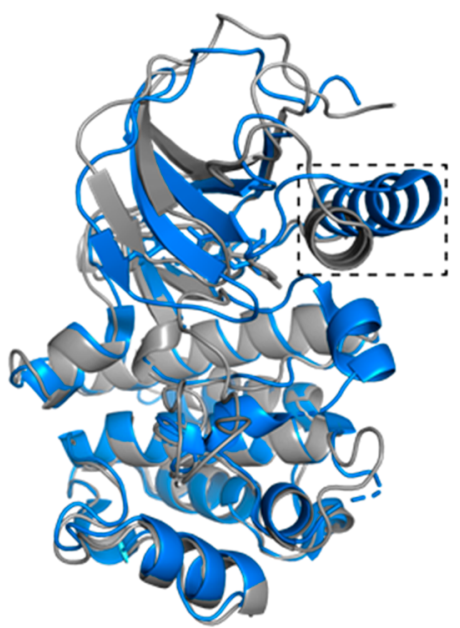

BRAF:2I vS BRAF:PLX4720
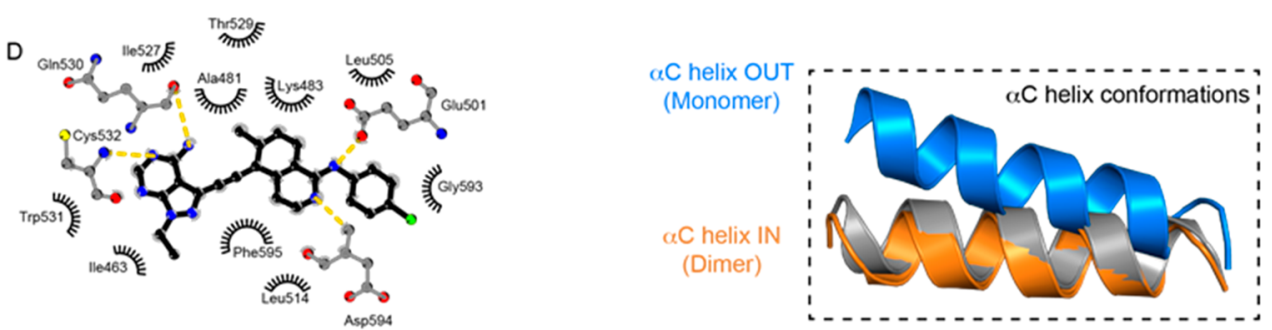

Figure 5. X-ray crystal structures of BRAF protein in complex with 2l. (A) Unbiased Fo-Fc electron density map contoured at $2.0 \sigma$ in green showing 21 binding in the ATP pocket of the kinase domain of BRAF. (B) Comparison of the BRAF:2l complex structure with (on left panel) the BRAF:sorafenib complex structure (PDB: $1 \mathrm{UWH}$ ) illustrating the dimeric ON-state conformation of the RAF kinase and with (right panel) the BRAF:PLX4720 complex structure (PDB: 4WO5) illustrating the monomeric OFF-state conformation of the RAF kinase. Lower panel represents a close-up view of the inward and outward conformations of the $\alpha \mathrm{C}$ helix. (C) Stick representation of 21 bound to BRAF kinase domain. BRAF residues interacting with $\mathbf{2 l}$ are represented in stick. Yellow dash lines represent hydrogen bonds. (D) Flat schematic representation of the binding mode of 21 with BRAF. Black sticks represent hydrophobic interaction and yellow dash lines represent hydrogen bonds.

BRAF kinase domain engaged by sulfonamide inhibitors, which display a laterally displaced helix $\alpha \mathrm{C}$ (Figure 5B). Compound $\mathbf{2 l}$ is stabilized in the ATP binding pocket by a mixture of hydrogen bonds and hydrophobic interactions (Figure 5C,D).

Specifically, the exocyclic amino group $\left(N^{4}\right)$ and the $N 5$ atom of the pyrazolo $[3,4-d]$ pyrimidine ring form hydrogen bonds with the carboxyl and the amide backbone of Gln530 and Cys532 from the hinge region, respectively. The pyrazolopyrimidine core is stabilized by hydrophobic interactions with the side chain of Phe583, Phe595, Trp531, and Ala481. The ethyl group at $\mathbf{1}$ position is poised to form hydrophobic interactions with the side chain of Ile463. The isoquinoline is stabilized by hydrophobic interactions with the Thr529, Ala481, Ile527, Lys483, and Leu514 as well as a hydrogen bond with the carboxyl backbone of Asp594 (part of the DFG loop). The aryl group of $\mathbf{2 l}$ occupies the hydrophobic pocket conventionally occupied by the phenyl ring of Phe595, resulting in an outward shift of the DFG loop that is characteristic of a type-II inhibitor binding mode (Figure 5C). The crystal structure of the BRAF:2l complex also nicely explains the SAR for the compound 2 series observed above. For example, the substitution of isoquinoline nitrogen by a carbon (as in $\mathbf{2 b}$ ) is unfavorable as it is expected to impair the hydrogen bond with the carboxyl backbone of Asp594 based on our crystal structure.

The binding mode of $\mathbf{2 l}$ revealed by our structure analysis implied that, similar to other inhibitors that preferentially bind to the dimer state of RAF, it might also promote kinase domain dimerization. To test this hypothesis further, we performed analytical ultracentrifugation analyses with recombinant BRAF kinase in the presence or absence of 2a (Figure S2B). We observed that at the concentration tested, recombinant BRAF kinase sedimented predominantly as a monomer in the absence of inhibitor, while in the presence of saturating concentration of $\mathbf{2 a}$, BRAF sedimented mostly as a dimer. These results showed that $\mathbf{2 a}$ promotes BRAF kinase dimerization. As suggested by our crystal structure showing 21 bound to the dimer state of BRAF and based on the similar structure of compounds $\mathbf{2 a}$ and $\mathbf{2 l}$, we predict that $\mathbf{2 l}$ also promotes BRAF kinase domain dimerization.

To further evaluate the potency and selectivity of $\mathbf{2 l}$ at inhibiting BRAF, it was screened against a collection of 57 distinct cancer cell lines at the National Cancer Institute according to the reported protocol (http://dtp.nci.nih.gov) (Table S3). Importantly, among the 57 cell lines, 10 harbor the $\mathrm{BRAF}^{\mathrm{V} 600 \mathrm{E}}$ mutation. The profiling data showed that 21 at 10 $\mu \mathrm{M}$ inhibited the proliferation of the diverse cell lines to various degrees. Notably 3 out of the 5 most sensitive cell lines (MALME-3M, MDA-MB-435, and SK-MEL-5) corresponded to melanoma cells harboring the BRAF ${ }^{\mathrm{V} 600 \mathrm{E}}$ mutation (Figure 6). Further studies confirmed that 21 inhibited the proliferation of these three cell lines in a dose-dependent manner with total growth inhibition (TGI) values of $7.1,4.6$, and $6.6 \mu \mathrm{M}$, respectively. Interestingly, one of the most sensitive cell lines in the panel, SK-MEL-2, is known to harbor a mutant NRAS 


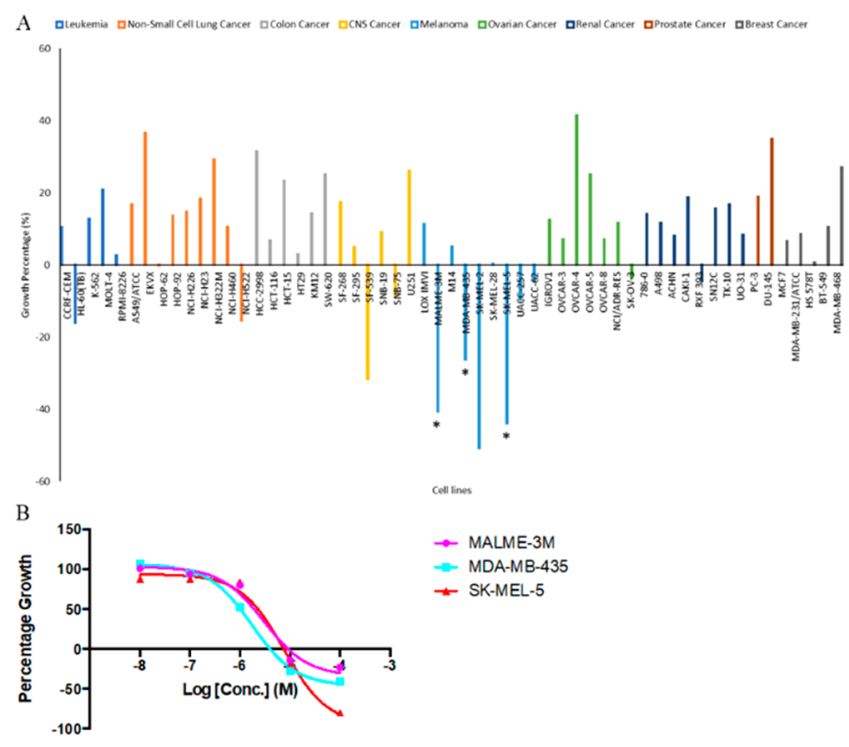

Figure 6. Compound 21 was profiled for antiproliferative effects against diverse cancer cell lines. (A) Compound 21 at $10 \mu \mathrm{M}$ preferentially inhibited the proliferation of a few out of a collection of 57 distinct cell lines. (B) Compound 21 inhibited dose-dependent growth inhibition of MALME-3M, MDA-MB-435, and SK-MEL-5 cells. * indicates sensitive cell lines bearing $\mathrm{BRAF}^{\mathrm{V} 600 \mathrm{E}}$.

(Q61R). As it has been established that elevated RAS activity drives RAF dimerization in cells, these data indicate that $\mathbf{2 l}$ might inhibit RAF dimers under certain cellular settings.

In summary, we have demonstrated that using a strategy of inhibitor rigidification, via ring closure, can lead to a dramatic increase in selectivity toward RAF kinases. Our structural and biochemical characterizations confirm that the rigidified inhibitors interact with BRAF kinase domains with a type-II binding mode that can drive RAF dimerization in vitro. The selectivity of our inhibitors reported here for RAF kinases is unprecedented for nonsulfonamide RAF inhibitors. We posit that a rigidification strategy could be readily applied to other RAF inhibitor scaffolds as a potential means to generate second-generation targeted therapies where first-generation inhibitors fail to function. Furthermore, rigidification could be a general strategy for enhancing inhibitor selectivity against other protein kinases, which may open up therapeutic opportunities not afforded by other approaches.

\section{ASSOCIATED CONTENT}

\section{S Supporting Information}

The Supporting Information is available free of charge on the ACS Publications website at DOI: 10.1021/acsmedchemlett.9b00194.

Supplementary Figures and Tables, experimental methods, X-ray crystallography data, synthetic procedures, and compound characterization data (PDF)

\section{Accession Codes}

Protein Data Bank code for BRAF-2l complex structure is 6NSQ.

\section{AUTHOR INFORMATION}

\section{Corresponding Author}

*E-mail: zhang.chao@usc.edu.

\section{ORCID}

Amir Assadieskandar: 0000-0002-0685-3608

Pierre Maisonneuve: 0000-0001-8292-5741

Chao Zhang: 0000-0003-0251-8156

\section{Author Contributions}

"These authors contributed equally to this work as first authors. The manuscript was written through contributions of all authors. All authors have given approval to the final version of the manuscript.

Notes

The authors declare no competing financial interest.

\section{ACKNOWLEDGMENTS}

We thank N. Graham and A. Delfarah for help with HR-MS data collection, National Cancer Institute for screening the compounds against cancer cell lines, and the Northeastern Collaborative Access Team beamlines for conducting diffraction work (NIH P41 GM103403 and S10 RR029205). This work was supported by National Science Foundation (CHE-1455306), Canadian Cancer Society Research Institute (704116), Canada Research Chair Program, and Canadian Institutes for Health Research (FDN143277). A.A. was supported by Stauffer Endowed Fellowship by USC Graduate School. C.Y. was supported by USC Dornsife Chemical Biology Training Program (T32). P.M. was supported by a TD Bank postdoctoral fellowship.

\section{ABBREVIATIONS}

RAF, rapidly accelerated fibrosarcoma; RAS, rat sarcoma; MEK, mitogen activated protein kinase; ERK, extracellular signal-regulated kinase; TGI, total growth inhibition

\section{REFERENCES}

(1) Daum, G.; Eisenmann-Tappe, I.; Fries, H. W.; Troppmair, J.; Rapp, U. R. The ins and outs of Raf kinases. Trends Biochem. Sci. 1994, 19, 474-80.

(2) Dhillon, A. S.; Hagan, S.; Rath, O.; Kolch, W. MAP kinase signalling pathways in cancer. Oncogene 2007, 26, 3279-90.

(3) Bond, C. E.; Whitehall, V. L. How the BRAF V600E Mutation Defines a Distinct Subgroup of Colorectal Cancer: Molecular and Clinical Implications. Gastroenterology research and practice 2018, 2018, 1.

(4) Davies, H.; Bignell, G. R.; Cox, C.; Stephens, P.; Edkins, S.; Clegg, S.; Teague, J.; Woffendin, H.; Garnett, M. J.; Bottomley, W.; Davis, N.; Dicks, E.; Ewing, R.; Floyd, Y.; Gray, K.; Hall, S.; Hawes, R.; Hughes, J.; Kosmidou, V.; Menzies, A.; Mould, C.; Parker, A.; Stevens, C.; Watt, S.; Hooper, S.; Wilson, R.; Jayatilake, H.; Gusterson, B. A.; Cooper, C.; Shipley, J.; Hargrave, D.; PritchardJones, K.; Maitland, N.; Chenevix-Trench, G.; Riggins, G. J.; Bigner, D. D.; Palmieri, G.; Cossu, A.; Flanagan, A.; Nicholson, A.; Ho, J. W.; Leung, S. Y.; Yuen, S. T.; Weber, B. L.; Seigler, H. F.; Darrow, T. L.; Paterson, H.; Marais, R.; Marshall, C. J.; Wooster, R.; Stratton, M. R.; Futreal, P. A. Mutations of the BRAF gene in human cancer. Nature 2002, 417, 949-54.

(5) Mann, M. B.; Black, M. A.; Jones, D. J.; Ward, J. M.; Yew, C. C.; Newberg, J. Y.; Dupuy, A. J.; Rust, A. G.; Bosenberg, M. W.; McMahon, M.; Print, C. G.; Copeland, N. G.; Jenkins, N. A. Transposon mutagenesis identifies genetic drivers of Braf(V600E) melanoma. Nat. Genet. 2015, 47, 486-95.

(6) Wilhelm, S.; Carter, C.; Lynch, M.; Lowinger, T.; Dumas, J.; Smith, R. A.; Schwartz, B.; Simantov, R.; Kelley, S. Discovery and development of sorafenib: a multikinase inhibitor for treating cancer. Nat. Rev. Drug Discovery 2006, 5, 835.

(7) Wan, P. T.; Garnett, M. J.; Roe, S. M.; Lee, S.; Niculescu-Duvaz, D.; Good, V. M.; Project, C. G.; Jones, C. M.; Marshall, C. J.; 
Springer, C. J. Mechanism of activation of the RAF-ERK signaling pathway by oncogenic mutations of B-RAF. Cell 2004, 116, 855-867.

(8) Wilhelm, S. M.; Adnane, L.; Newell, P.; Villanueva, A.; Llovet, J. M.; Lynch, M. Preclinical overview of sorafenib, a multikinase inhibitor that targets both Raf and VEGF and PDGF receptor tyrosine kinase signaling. Mol. Cancer Ther. 2008, 7, 3129-3140.

(9) Mousa, A. B. Sorafenib in the treatment of advanced hepatocellular carcinoma. Saudi journal of gastroenterology: official journal of the Saudi Gastroenterology Association 2008, 14, 40.

(10) Van Allen, E. M.; Wagle, N.; Sucker, A.; Treacy, D. J.; Johannessen, C. M.; Goetz, E. M.; Place, C. S.; Taylor-Weiner, A.; Whittaker, S.; Kryukov, G. V.; Hodis, E.; Rosenberg, M.; McKenna, A.; Cibulskis, K.; Farlow, D.; Zimmer, L.; Hillen, U.; Gutzmer, R.; Goldinger, S. M.; Ugurel, S.; Gogas, H. J.; Egberts, F.; Berking, C.; Trefzer, U.; Loquai, C.; Weide, B.; Hassel, J. C.; Gabriel, S. B.; Carter, S. L.; Getz, G.; Garraway, L. A.; Schadendorf, D. Dermatologic Cooperative Oncology Group of, G. The genetic landscape of clinical resistance to RAF inhibition in metastatic melanoma. Cancer Discovery 2014, 4, 94-109.

(11) Bollag, G.; Hirth, P.; Tsai, J.; Zhang, J.; Ibrahim, P. N.; Cho, H.; Spevak, W.; Zhang, C.; Zhang, Y.; Habets, G. Clinical efficacy of a RAF inhibitor needs broad target blockade in BRAF-mutant melanoma. Nature 2010, 467, 596.

(12) Zhang, C.; Spevak, W.; Zhang, Y.; Burton, E. A.; Ma, Y.; Habets, G.; Zhang, J.; Lin, J.; Ewing, T.; Matusow, B. RAF inhibitors that evade paradoxical MAPK pathway activation. Nature 2015, 526, 583.

(13) Tsai, J.; Lee, J. T.; Wang, W.; Zhang, J.; Cho, H.; Mamo, S.; Bremer, R.; Gillette, S.; Kong, J.; Haass, N. K. Discovery of a selective inhibitor of oncogenic B-Raf kinase with potent antimelanoma activity. Proc. Natl. Acad. Sci. U. S. A. 2008, 105, 3041-3046.

(14) Rheault, T. R.; Stellwagen, J. C.; Adjabeng, G. M.; Hornberger, K. R.; Petrov, K. G.; Waterson, A. G.; Dickerson, S. H.; Mook, R. A., Jr; Laquerre, S. G.; King, A. J. Discovery of dabrafenib: A selective inhibitor of Raf kinases with antitumor activity against B-Raf-driven tumors. ACS Med. Chem. Lett. 2013, 4, 358-362.

(15) Assadieskandar, A.; Yu, C.; Maisonneuve, P.; Liu, X.; Chen, Y.C.; Prakash, G. S.; Kurinov, I.; Sicheri, F.; Zhang, C. Effects of rigidity on the selectivity of protein kinase inhibitors. Eur. J. Med. Chem. 2018, 146, 519-528.

(16) Liu, X.; Kung, A.; Malinoski, B.; Prakash, G. S.; Zhang, C. Development of alkyne-containing pyrazolopyrimidines to overcome drug resistance of Bcr-Abl Kinase. J. Med. Chem. 2015, 58, 92289237.

(17) Kitade, M.; Yamashita, S.; Ohkubo, S. Bicyclic compound or salt thereof. U.S. Patent 8,912,181, December 16, 2014.

(18) Kung, A.; Chen, Y.-C.; Schimpl, M.; Ni, F.; Zhu, J.; Turner, M.; Molina, H.; Overman, R.; Zhang, C. Development of specific, irreversible inhibitors for a receptor tyrosine kinase EphB3. J. Am. Chem. Soc. 2016, 138, 10554-10560.

(19) Smith, A. L.; DeMorin, F. F.; Paras, N. A.; Huang, Q.; Petkus, J. K.; Doherty, E. M.; Nixey, T.; Kim, J. L.; Whittington, D. A.; Epstein, L. F. Selective inhibitors of the mutant B-Raf pathway: discovery of a potent and orally bioavailable aminoisoquinoline. J. Med. Chem. 2009, $52,6189-6192$

(20) Chao, Q.; Deng, L.; Shih, H.; Leoni, L. M.; Genini, D.; Carson, D. A.; Cottam, H. B. Substituted isoquinolines and quinazolines as potential antiinflammatory agents. Synthesis and biological evaluation of inhibitors of tumor necrosis factor $\alpha$. J. Med. Chem. 1999, 42, 3860-3873.

(21) Chan, D. M.; Monaco, K. L.; Wang, R.-P.; Winters, M. P. New $\mathrm{N}$-and $\mathrm{O}$-arylations with phenylboronic acids and cupric acetate. Tetrahedron Lett. 1998, 39, 2933-2936.

(22) Gharat, L. A.; Banerjee, A.; Khairatkar-Joshi, N.; Kattige, V. G. Bicyclic compounds as mPGES-1 inhibitors. U.S. Patent 9,006,257, April 14, 2015.

(23) Zhang, C.-H.; Zheng, M.-W.; Li, Y.-P.; Lin, X.-D.; Huang, M.; Zhong, L.; Li, G.-B.; Zhang, R.-J.; Lin, W.-T.; Jiao, Y. Design, synthesis, and structure-activity relationship studies of 3-(Phenyl- ethynyl)-1 H-pyrazolo [3, 4-d] pyrimidin-4-amine derivatives as a new class of Src inhibitors with potent activities in models of triple negative breast cancer. J. Med. Chem. 2015, 58, 3957-3974.

(24) Liu, X.; Kung, A.; Malinoski, B.; Prakash, G. K.; Zhang, C. Development of Alkyne-Containing Pyrazolopyrimidines To Overcome Drug Resistance of Bcr-Abl Kinase. J. Med. Chem. 2015, 58, 9228-37.

(25) Zhang, C.; Spevak, W.; Zhang, Y.; Burton, E. A.; Ma, Y.; Habets, G.; Zhang, J.; Lin, J.; Ewing, T.; Matusow, B.; Tsang, G.; Marimuthu, A.; Cho, H.; Wu, G.; Wang, W.; Fong, D.; Nguyen, H.; Shi, S.; Womack, P.; Nespi, M.; Shellooe, R.; Carias, H.; Powell, B.; Light, E.; Sanftner, L.; Walters, J.; Tsai, J.; West, B. L.; Visor, G.; Rezaei, H.; Lin, P. S.; Nolop, K.; Ibrahim, P. N.; Hirth, P.; Bollag, G. RAF inhibitors that evade paradoxical MAPK pathway activation. Nature 2015, 526, 583-6.

(26) Poulikakos, P. I.; Zhang, C.; Bollag, G.; Shokat, K. M.; Rosen, $\mathrm{N}$. RAF inhibitors transactivate RAF dimers and ERK signalling in cells with wild-type BRAF. Nature 2010, 464, 427-30. 